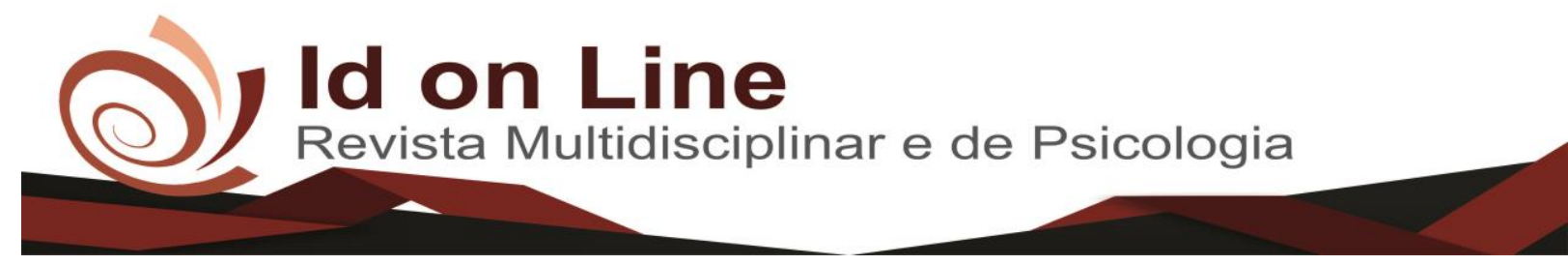

Comment

\title{
O Uso dos Jogos no Ensino da Matemática
}

Marcelo Lopes Leão Barros ${ }^{1}$; Clenilson Panta Angelim²

\begin{abstract}
Resumo: Esse artigo tem como objetividade difundir o jogo matemático como uma das principais alternativa para tornar o ensino da matemática mais dignificante e acolhedor, aumentando assim a motivação e o despertar do discente pela Matemática. $\mathrm{O}$ uso do jogo traz um aprendizado com grandes perspectivas no desenvolvimento da capacidade mental e intelectual do discente tornando gratificante, satisfatório e significativo o ensino da matemática, promovendo assim o cálculo mental, indução pela a busca de estratégias, dominar o uso das operações fundamentais, o construtivismo dos conceitos e o aperfeiçoamento do raciocínio lógico. Além de desenvolver o gosto e o prazer pela a matemática.
\end{abstract}

Palavras-chave: Educação. Matemática. Jogos.

\section{The use of the Games in the Teaching of Mathematics}

Abstract: This article aims to disseminate the mathematical game as one of the main alternatives to make the teaching of mathematics more dignifying and welcoming, thus increasing the student's motivation and awakening for Mathematics. The use of the game brings a learning with great perspectives in the development of the mental and intellectual capacity of the student making the teaching of mathematics satisfactory and meaningful, thus promoting the mental calculation, induction by the pursuit of strategies, mastering the use of fundamental operations, the constructivism of concepts and the improvement of logical reasoning. In addition to developing taste and pleasure for mathematics.

Keywords: Education. Mathematics. Games.

\section{Introdução}

O ensino matemático tem sido de grande complexidade e intrigante, porque sua aprendizagem é dependente dos mais variados fatores. Segundo Groenwald \& Timm (2007), para se aprender a matemática é necessário desenvolver os mais variados estímulos cognitivos e psicológicos, desenvolvendo assim o raciocínio lógico, e que estimule o livre pensamento do discente, no estimulo a criação e a resolução de problemas.

\footnotetext{
1 Graduando do curso de licenciatura plena em matemática, Faculdade de Ciências Humanas do Sertão Central - Facusc, E-mail: mlleobarros@gmail.com

2 Professor do curso de licenciatura plena em matemática, Faculdade de Ciências Humanas do Sertão Central -Fachusc, E-mail: clenilson2005@yahoo.com.br
} 
É nesse sentido, que os docentes da educação matemática e outras ciências que se utiliza do jogo educativo, busca engrandecer e motivar o aprendizado, desenvolver a autoconfiança, organização, concentração, atenção, raciocínio lógico-dedutivo e senso cooperativo, aumentando a socialização, promovendo o interesse e a partilha de ideias entre discente/docente.

Tendo em vista tais aspectos, e vendo que grande parte dos discentes não mostra um importante interesse pela Matemática, diante do pressuposto que é tudo um bicho de sete cabeças complicado e difícil, no entanto, por sua vez, os discentes tem um rápido entendimento das regras e passam a participar de forma significativa das atividades lúdicas, tornando assim o uso dos jogos um importante complemento no estudo dessa disciplina, pois o jogo é um importante estimulante e socializante, e essencial para a aprendizagem e diversão ajudam muito no desenvolvimento de capacidades, conhecimentos, atitudes, bem como de habilidades cognitivas e sociais.

Nesse sentido, autores como Groenwald e Timm (2007) incentivam o uso de jogos e curiosidades adaptados ao ensino da Matemática, para mudar a rotina na sala de aula, despertar o interesse do aluno e fazê-lo gostar de aprender essa disciplina. O caráter lúdico parece desenvolvedor de técnicas intelectuais e incentivador de relações sociais.

Além disso, Batllori (2006) oriente que, através dos jogos, é possível incentivar a aceitação de normas e hierarquias, melhorar o trabalho em equipe e o respeito ao próximo, por que, o discente quando pratica o jogo na rua, na escola, no acampamento e brinca com colegas de escola ou amigos com proximidade com a sua idade, com colegas ou amigos de variadas procedências e culturas, se cria um grande vinculo socializante e um ser social.

Diante disso, fica entendido assim, que a demonstração de total apreço e entusiasmo dos discentes perante a aplicação dos jogos tem que ter grande aproveitamento na busca de importante e novo conhecimento matemático, na consolidação dos que possuem um grande saber matemático e no auxilio do desenvolvimento completo do discente.

Diversos autores, como Borin e Batllori, referenciam e ressaltam uma grande mudança no desenvolvimento de uma didática mais adaptada na utilização de jogos.

Borin (1996) considera importante, que nesse processo, o discente passa a ser um participante ativo na aprendizagem, e na construção do seu próprio saber e, deixando de ser apenas um ouvinte passivo. 
Batllori (2006) destaca que tal manifestação natural da criança, sem nenhuma censura e convenções, demonstra seu ser, sendo uma forma de aprendizado para os professores, ajudando também quanto a elaboração de novas estratégias.

Outra importante dimensão citada por Batllori (2006), é o lado socializante dos jogos, pois com eles há o aprendizado da convivência e do respeito às outras pessoas e culturas, em especial quando interagem juntas para alcançar um objetivo comum. A relevância desse aspecto é observada no Currículo Básico para a Escola Publica do Estado do Paraná.

\begin{abstract}
Sendo uma espécie social o ser humano se caracteriza pela construção de sua individualidade através da relação com o outro. O sujeito se constitui, assim, em virtude de processos múltiplos de interação com o meio sócio-cultural, pela presença de outros indivíduos e/ou objetivo culturalmente inseridos e definidos. (LIMA, 2003, p. 18).
\end{abstract}

Por fim, podemos observar nos Parâmetros Curriculares Nacional (BRASIL, 1998) que um aspecto de grande importância nos jogos é o desafio que eles provocam nos discentes, despertando o interesse e prazer por aprender matemática. Dessa forma, demonstra a importância de inserir jogos na cultura escolar, cabendo ao docente analisar e avaliar a potencialidade educativa dos diferentes jogos e o aspecto curricular que deseja desenvolver.

\title{
Fundamentação Teorica
}

São abrangente e longo os debates diante a complexidade dos notáveis problemas relatados e encontrados em sala de aula diante do porque o aluno deixa a escola sem saber e sem entender parte da Matemática.

No objetivo de diminuir consideravelmente esses problemas, pensou-se na utilização dos jogos, com participação de conteúdos matemáticos, a serem trabalhados em aula.

Mesmo a história demonstra que tais práticas não são novidade, conforme Kishimoto (Apud FERRAREZI, 2005) Platão se utilizou de jogos para apresentar a Matemática de forma concreta, para num outro nível usar abstrações. Também foi uma prática romana a utilização dos jogos para se transmitir valores e costumes. há relatos que os Jesuítas, também praticavam jogos de emulação ${ }^{1}$ visando o aperfeiçoamento da capacidade oratória dos discentes.

\footnotetext{
${ }^{1}$ Rivalidade, competição
} 
Com tanto, não é novidade a utilização de jogos como facilitador do aprendizado, independentemente de qual disciplina vai ser estudada.

Borin (1996) oferece como justificativa à introdução de vários jogos nas aulas de matemática, a possibilidade de minimizar bloqueios dos discentes que temem a Matemática e sentem dificuldades para aprendê-la. A situação de desafio no jogo, leva o discente a uma maior motivação, se envolvendo, enquanto trabalham com Matemática. Batllori (2006) escreve sobre algumas capacidades a serem desenvolvidas com o jogo, tais como talento, astúcia, segurança, confiança, comunicação, enfretamento do medo, imaginação, aquisição de novos conhecimentos, acuidade de observação. Também mostra os jogos como fator importante para o desenvolvimento da capacidade de resolução de problemas, pois parecem ampliarem as habilidades manuais além da lógica.

\section{A Aula de Matemática e o Jogo}

O fato de inserir jogos nas aulas de matemática e em outras disciplinas é uma forma lúdica de demonstração do conteúdo, criando uma nova expectativa para que o discente aprenda e estabelecer um vínculo mais forte na relação docente/discente, concedendo espaço ao docente na descoberta das incertezas com relação aos conteúdos que representa alguma dificuldade do discente.

Encontramos diversos tipos de jogos matemáticos, como os que já compramos prontos, como os que tem a necessidade de ser confeccionados e os virtuais. Pois esses jogos podem ser usados pelo docente e seus discentes, transformando o dia-a-dia das aulas de matemática, seduzindo o discente pela apresentação lúdica e diferenciada. Desta forma, compete ao docente pesquisar e observar quais os jogos que melhor assemelham aos conteúdos a serem trabalhados.

Portanto, constata-se a necessidade de um estudo mais complexo em busca da forma mais adequada para demonstração e desenvolvimento desses recursos, nas disciplinas de matemática, como uma maneira possível de atingir os objetivos desejados.

Não adianta só saber jogar e conhecer esses jogos, é necessário que o docente consiga conciliar de forma interativa e dinâmica esse recurso, para não cair no costume rotineiro de sala de aula. 
A vantagem de se trabalhar com jogos é a facilidade da interdisciplinaridade da série trabalhada. Além de despertar a atenção da maioria dos discentes. Pois quando estão jogando, distraem-se sem a obrigação de aprender algo imposto pelas propostas apresentadas habitualmente pelos docentes.

Esse momento de descontração dos discentes podem ser aproveitado de maneira mais ampla em favor do docente, trabalhando assim, os conteúdos necessários, de forma mais prazerosa e fazendo com que o discente adapte-se a ele sem notar e sem questionar porque não entende Matemática.

Esse pensamento é partilhado por diversos autores, como BORIM (1996) e MALBA TAHAN (1965).

\section{Perspectiva Interdisciplinar do uso de Jogos em Matemática}

Uma perspectiva e vantagem ao se trabalhar jogos em sala de aula é o facilitador de interações com as outras disciplinas da série trabalhada.

Podemos trabalhar os jogos matemáticos com a participação de variadas disciplinas como:

- Artes - confecção dos jogos: utilização de diferentes técnicas e materiais.

- Ciências - uso de materiais reciclados para a confecção de jogos, oportunizando o estudo a respeito da reciclagem.

- Geografia - localizar em mapas os países onde foram originados os jogos.

- História - trabalhar a origem dos jogos.

- Língua Estrangeira - expressões e nomes usados em alguns jogos que não são palavras da língua portuguesa.

- Português - trabalhar a leitura e a interpretação textual.

\section{Metodologia}

O método empregado nesse artigo foi desenvolvido através de pesquisas bibliográficas onde foram pesquisados diversos instrumentos de leitura como livros, trabalhos, revistas, 
artigos e internet sobre o tema estudado, relacionado ao uso de jogos no ensino da matemática, visando mostrar as contribuições que os jogos causam no processo de ensino-aprendizagem do discente. Mostrar um estudo voltado para as melhorias e vantagens no desempenho educacional e pessoal dos educandos que usam o jogo como meio de orientação dos estudos, e que vem trazendo desenvolvimentos importantes para a vida do discente, e docente, e assim trazendo um grande rendimento para o discente e melhorias na educação.

\section{Considerações Finais}

É possível destacar e observar que o trabalho com jogos matemáticos, aumenta o desempenho e a motivação do discente, conseguindo que grandes partes dos discentes passem a ter as aulas de Matemática como uma aula harmoniosa e prazerosa, sem se preocupar com as dificuldades impostas na sala de aula. Desenvolvendo o pensamento lúdico do discente, e assim dando uma visão no aproveitamento do aprendizado do discente.

Diante da perspectiva de engrandecer o ensino, entende-se que o jogo tem boa aplicabilidade e pode ser utilizado como parâmetro inicial para a utilização em diversas disciplinas. No entanto, é importante frisar que à atuação do docente não deve limitar-se apenas aos jogos, mas devem ser buscadas tantas outras alternativas que se adequem ao perfil dos discentes e ao conteúdo estudado.

\section{Referências}

BARTLLORI, Jorge. Jogos para treinar o cérebro. Tradução de Fina Iñiguez. São Paulo: Madras, 2006.

BORIN, Júlia. Jogos e resolução de problema: uma estratégia para as aulas de matemática. São Paulo: IME - USP, 1996

BRASIL. Secretaria de Educação Fundamental. Parâmetros curriculares nacionais: Matemática / Secretaria de Educação Fundamental. Brasília: MEC/SEF, 1998.

FERRAREZI, Luciana Aparecida. Criando novos tabuleiros para o jogo Tri-Hex e sua validação didático-pedagógica na formação continuada de professores de Matemática: 
uma contribuição para a Geometria das séries finais do Ensino Fundamental. UNESP Universidade Estadual Paulista, Instituto de Geociências e Ciências Exatas, 2005. Dissertação de Mestrado. Orientador: Laurizete Ferragut Passos.

GROENWALD, Claudia Lisete Oliveira; TIMM, Ursula Tatiana. Utilizando curiosidades e jogos matemáticos em sala de aula. Retirado em 15 de maio de 2007, às $20 \mathrm{~h}$ e 55 min do site http://paginas.terra.com.br/educacao/calculu/artigos/professores/utilizandojogos.htm

LIMA, Elvira Cristina de Souza. Algumas questões sobre o desenvolvimento do ser humano e a aquisição de conhecimentos na escola. In: PARANÁ, Governo do Estado do. Currículo Básico para a Escola Pública do Estado do Paraná: versão eletrônica. $3^{a}$ edição. 2003. Retirado em 13 de julho de 2007 às 13:00 do site

http://www.diaadiaeducacao.pr.gov.br/portals/portal/institucional/def/pdf/curriculo_basico_es cola_pub_pr.pdf

MARANGON, Cristiane. Um jogo para treinar o cálculo mental. Revista Nova Escola, São Paulo: Editora Abril S.A., edição 177, p. 58-59, nov. 2004.

TAHAN, Malba. Didática da Matemática. Vol. 1 e 2. São Paulo: Saraiva Livreiros Editoriais. 1965.

\section{Como citar este artigo (Formato ABNT):}

BARROS, Marcelo L. L.; ANGELIM, Clenilson P. O uso dos jogos no ensino da matemática. Id on Line Revista ultidisciplinar e de Psicologia, 2017, vol.12, n.39, p.452-458. ISSN: 1981-1179.

Recebido: 28.12.2017

Aceito: 02.01 .2018 